\title{
On the Structure of Indefinite Possessives
}

\author{
Gianluca Storto \\ University of California, Los Angeles
}

I present evidence that indefinite possessives display some peculiar semantic properties distinguishing them from other types of possessive DPs. In particular, indefinite possessives do not license contextual interpretations, which are instead available for the corresponding definite possessives and possessive partitives. This semantic asymmetry argues against existing theories according to which indefinite possessives are structurally equivalent to definite possessives (Kayne (1994)) or to possessive partitives (Barker (1998); Zamparelli (1998)).

The unavailability of contextual interpretations for indefinite possessives is accounted for in Storto ([to appear]) in terms of the discourse semantics of these DPs: indefinite possessives cannot be interpreted as discourse-specific DPs. This semantic peculiarity is due to the interaction between their partitive structure and the indefiniteness of the nominal embedded under $o f$. The implementation of this idea proposed in Storto ([to appear]), however, is not compatible with the "classic" formulation of the Partitive Constraint. I show that this proposal can be maintained under a reformulation of the Partitive Constraint along the lines of de Hoop (1997), and draw some conclusions on the structural complxity of indefinite possessives in a crosslinguistic perspective.

\section{Introduction: The Structure of Indefinite Possessives}

I use the label indefinite possessives to refer to nominals like those exemplified in (1). In this category I group both English so-called double genitives (1a) and the seemingly structurally simpler possessive DPs introduced by an indefinite determiner in languages like Italian (1b). In this paper I argue that the latter have the same amount of structural complexity as English double genitives.
a. two dogs of John's
b. due cani di Gianni

[Italian]

The characterization of the syntactic and semantic structure of this type of DPs has been a matter of debate in the literature. Intuitively, the null hypothesis would be that the structure of indefinite possessives is essentially the same as that of definite possessives, exemplified in (2).
a. John's two dogs
b. i due cani di Gianni

[Italian]

This hypothesis seems supported by the surface form of these types of DPs in Italian. The Italian indefinite and definite possessives in (1b) and (2b) seem to differ 
from each other only in the definiteness of their determiners. That is, these two DPs do not seem to differ from each other more than the two DPs due cani 'two dogs' and $i$ due cani 'the two dogs' do. On the other hand, the form of English indefinite possessives seems to suggest that the null hypothesis might not be completely correct. English double genitives (1a) are morphologically more complex than the corresponding Saxon genitives (2a).

The greater morphological complexity of English indefinite possessives has been tackled in two completely different ways in recent literature. Kayne (1994) has proposed that the morphological complexity of English double genitives can be traced to the application of some movement operations which further derive the surface structure of double genitives from the surface structure of Saxon genitives. Barker (1998) and Zamparelli (1998), instead, have proposed that double genitives are structurally more complex than Saxon genitives, their structure being essentially equivalent to that of possessive partitives (3).

a. two of John's dogs

b. due dei cani di Gianni

[Italian]

The main claim advanced by this paper is that neither of these two positions, as they stand, can be correct. Indefinite possessives, in English and in other languages, differ from both definite possessives and possessive partitives. I will first briefly present the analyses of Kayne (1994) and Barker (1998)/Zamparelli (1998) and then develop my argument in the following sections. For the moment I will concentrate on the discussion of indefinite possessives in English, returning to a more general crosslinguistic perspective at the end of the paper.

\subsection{Kayne (1994)}

The analysis of indefinite possessives proposed in Kayne (1994) differs only minimally from the null hypothesis expounded above. According to Kayne the surface structure of double genitives (4b) is derived from the structure of Saxon genitives by the application of a movement operation which displaces the NP/QP two pictures to the Spec,DP position.

$$
\begin{aligned}
& \text { a. }\left[_ { \mathrm { DP } } \operatorname { S p e c } \left[\left[_{\mathrm{D}^{\prime}} \mathrm{D}_{\mathrm{def}}\left[\left[_{\mathrm{AgrP}} \operatorname{John}\left[_{\mathrm{Agr}} \text { 's }\left[_{\mathrm{NP} / \mathrm{QP}} \text { two pictures }\right]\right]\right]\right]\right]\right.\right. \\
& \text { b. }\left[_{\mathrm{DP}}\left[\left[_{\mathrm{NP} / \mathrm{QP}} \text { two pictures }\right]_{i}\left[_{\mathrm{D}^{\prime}} \mathrm{D}_{\text {indef }}\left[{ }_{\mathrm{AgrP}} \text { John }\left[{ }_{\mathrm{Agr}} \text { 's } t_{i}\right]\right]\right]\right]\right.
\end{aligned}
$$

Kayne proposes that this additional movement operation (and the insertion of the weak preposition of in D) is obligatory in double genitives as a consequence of the indefinite nature of their (null) determiner. The definite determiner in (4a) is indeed involved in licensing Case on the DP John in Spec,AgrP. Indefinite D is not a Case licensor, but movement of NP/QP to Spec,DP and insertion of of in D turn the latter into a Case licensor, thus rescuing the structure.

The relevant aspect for the discussion to follow is that, modulo the extra movement in (4b) triggered by the indefiniteness of D, in Kayne (1994) indefinite possessives are equivalent to definite possessives. That is, modulo the definiteness value of their $\mathrm{D}$, the two constructions are expected to be semantically equivalent. 


\subsection{Barker (1998) and Zamparelli (1998)}

Both Barker (1998) and Zamparelli (1998) defend a version of what Barker calls the partitive hypothesis. According to this hypothesis double genitives are a type of partitive DP. The DPs in (1a) and (3a) are both mapped to the same semantic structure in (5), the surface difference between the two DPs being accounted for in terms of the position in which the noun dogs is spelled out.

$$
\left[{ }_{D P_{1}} \text { two }\left[{ }_{X P} \operatorname{dog} s_{i}\left[x_{X^{\prime}} \text { of part }\left[_{D P_{2}} J_{o h n ' s ~ d o g s} I\right]\right]\right]\right.
$$

In partitive DPs the semantics of partitive of imposes the restriction that the whole $\mathrm{DP}_{1}$ denotes a proper part of the denotation of $\mathrm{DP}_{2}$. The proper partitivity requirement imposed by partitive of obtains the result that XP in partitive DPs cannot semantically combine with the definite determiner, unless XP is subject to additional modification. ${ }^{1}$ This explains why both possessive partitives and indefinite possessives display the peculiar semantic property that Barker (1998) labels anti-uniqueness (exemplified in (6)).
a. *I met the one of John's friends.
b. I met the one of John's friends that you pointed out last night.
c. *I met the friend of John's.
d. I met the friend of John's that you pointed out last night.

Under the analysis in Barker (1998)/Zamparelli (1998), indefinite possessives differ from partitive possessives only at a very superficial level: both constructions map to the same semantic structure, a conclusion which is refuted in the next section.

\section{The Contextual Interpretation of Possessive DPs}

Both an approach to indefinite possessives along the lines proposed by Kayne (1994) and an approach along the lines of Barker (1998)/Zamparelli (1998) make the prediction that indefinite possessives should not have a semantics different from either definite possessives or possessive partitives. That is, indefinite possessives are expected, under these theories, to license the same semantic interpretations as definite possessives (modulo the effects of their indefinite vs. definite specification) or possessive partitives. Evidence pointed out in Storto ([to appear]) shows that this is not the case. Indefinite possessives do not license contextual interpretations, which are instead available for definite possessives and possessive partitives.

In order to discuss the relevant data, I need to say a few words on the semantics of possessive DPs. These DPs always involve two nominals, a nominal denoting the possessor and a nominal denoting the possessum (the possessed object). Informally, the possessor nominal behaves semantically as a modifier of the possessum nominal: the denotation of a possessive DP is an object of the kind described by the possessum which bears some relation to the object denoted by the 
possessor. Possessive DPs do not only license the interpretation under which the relation holding between possessor and possessum is one of ownership or possession proper. It has long been argued in the literature that the interpretation of possessives can be easily determined by their context of use, which specifies the nature of the relation holding between possessor and possessum.

The semantic peculiarity of indefinite possessives I focus on in this paper consists exactly in their inability of licensing this interpretive flexibility. That is, indefinite possessives - differently from definite possessives and possessive partitivesseem to be restricted to the interpretation according to which the relation holding between possessor and possessum is a relation of ownership or possession proper. ${ }^{2}$ Consider the paradigm in (7):

(7) Yesterday John and Paul were attacked by (different) groups of dogs;

a. ...unfortunately John's dogs were pitbulls.

b. ... unfortunately some of John's dogs were pitbulls.

c. \#... unfortunately some dogs of John's were pitbulls.

John's dogs in (7a) can be easily interpreted as denoting the set of dogs that attacked John which is introduced in the context-setting sentence. The same kind of interpretation is available for the possessive partitive some of John's dogs in (7b). The indefinite possessive some dogs of John's in (7c), instead, does not seem able to license this interpretation. This last DP can only be interpreted as denoting a subset of the set of dogs owned by John, which makes the sentence in (7c) pragmatically odd as a continuation of the context-setting sentence.

This semantic peculiarity of indefinite possessives poses serious problems for analyses which - in some way or other-try to reduce the syntactic and semantic structure of this class of DPs to other types of possessive DPs. The contrast between (7b) and (7c) clearly indicates that the analyses of indefinite possessives proposed by Barker (1998) and Zamparelli (1998) cannot be correct as they stand. Within these theories indefinite possessives are semantically equivalent to possessive partitives, which does not leave room to account for their contrasting interpretive possibilities. The contrast between (7a) and (7c) is instead problematic for Kayne's (1994) analysis. Under this approach indefinite possessives are expected to differ from definite possessives only in terms of their definiteness specification, but it can be argued that the contrast between (7a) and (7c) cannot be accounted for in terms of this semantic distinction between these two types of DPs.

I will return to this last point shortly, after having proposed an account for the derivation of contextual readings in possessive DPs. Before doing this, however, I would like to point out that the absence of contextual interpretations in indefinite possessives does not derive from some "masking" effect due to the availability of the more "ordinary" ownership interpretation for the relation holding between possessor and possessum in DPs like some dogs of John's in (7c). This hypothesis could not account for the unavailability of a contextual interpretation for DPs like some hurricanes of John's in (8), which does not license the ownership interpretation. 
\#John and Paul (two famous explorers) found themselves of ten in the midst of hurricanes. Some hurricanes of John's killed various members of his expedition, but he was never injured.

\subsection{How the Contextual Interpretation Is Derived}

Leaving indefinite possessives aside for a moment, the possibility for the interpretation of possessive DPs to be determined by their context of use indicates that the nature of the relation holding between possessor and possessum is not fully specified by the syntax of these constructions. As argued by Barker (1995), only for a subclass of possessive DPs-which he labels lexical possessives- the nature of the relation holding between possessor and possessum is determined by the lexical semantics of the possessum nominal, which denotes a relational entity. ${ }^{3}$ For all other extrinsic possessives the nature of the relation they involve needs to be specified by the context. This explains why possessive DPs like John's hurricane sound odd when uttered out of the blue: the nature of the relation holding between possessor and possessum in this DP cannot be recovered from its (empty) context of use. ${ }^{4}$

The possibility for a DP like John's dogs in (7a) to recover the nature of the relation holding between possessor and possessum from its context of use can be accounted for in (at least) two ways. One possibility is that the underspecified relation is syntactically encoded by a pronominal-like relational category which looks for an antecedent in the context. The contextual interpretation for the possessive in (7a) would then be due to the possibility of linking the pronominal category contained in this DP to an antecedent-the relation $\lambda y \lambda x$. attack $(y)(x)$-introduced in the context-setting sentence. Alternatively, the nature of the relation involved in the possessive DP in (7a) could be determined by the discourse semantics of the DP itself. This DP, being definite, is subject to Heim's (1982) familiarity condition, which restricts its denotation to discourse-familiar entities. The DP can thus be linked to a discourse referent introduced in the context-setting sentence-the discourse referent for the set of dogs which attacked John - which specifies the nature of the relation holding between possessor and possessum.

Under either approach, the availability of the contextual interpretation for possessive partitives like some of John's dogs in (7b) follows from their partitive semantics: partitive DPs are restricted to denote part of the entity denoted by the nominal embedded by partitive of. In (7b) this is the definite possessive DP John's dogs, which can be interpreted as denoting the group of dogs that attacked John introduced in the context-setting sentence: in possessive partitives the nature of the possessive interpretation is determined by the interpretation of their embedded DP.

The unavailability of a contextual interpretation for the indefinite possessive in (7c) highlights the fact that this class of DPs is not able to recover a relation which has been made salient in their context of use. It is important to notice that this semantic property of indefinite possessives cannot be simply reduced to their indefinite specification. That is, the asymmetry existing between definite possessives and indefinite possessives in licensing contextual interpretations cannot be a reflex of the difference in the definiteness value of their determiners. Indeed, in- 
definite DPs in general can be used to refer to (subsets of) discourse-familiar plural entities under a discourse-specific interpretation. For example, under the most easily available interpretation of (9) the indefinite DP two girls denotes two of the girls introduced in the first sentence.

(9) Some boys and some girls entered the room. Two girls were wearing red sweaters.

If indefinite possessives differ from definite possessives only in the definiteness value of their determiner, one would expect some dogs of John's in (7c) to license the interpretation under which it denotes a subset of the dogs introduced in the context-setting sentence, contrary to the attested data. This is why the contrast between (7a) and (7c) is problematic for Kayne's (1994) analysis of indefinite possessives, too. In Kayne's proposal indefinite possessives differ from definite possessives only in that their determiner is indefinite, which does not seem to be enough to derive the contrast in their ability to license contextual interpretations.

\section{A First Account: Storto ([to appear])}

The unavailability of contextual interpretations for indefinite possessives is accounted for in Storto ([to appear]) by adopting a modified version of the partitive hypothesis. Indefinite possessives are analyzed as DPs having an essentially partitive structure, but it is proposed that they differ from possessive partitives in the discourse semantics of the DP embedded by partitive of $\left(\mathrm{DP}_{2}\right.$ in (5)). $\mathrm{DP}_{2}$ in indefinite possessives is necessarily indefinite itself.

It can be argued that the definite specification of $\mathrm{DP}_{2}$ is a necessary ingredient for the derivation of contextual readings in possessive partitives. In these DPs the possessive relation is established within the embedded DP, the whole $\mathrm{DP}_{1}$ denoting part of the entity denoted by $\mathrm{DP}_{2}$. The meaning of a possessive partitive is - so to speak- "anchored" to the context by the interpretation of $\mathrm{DP}_{2}$. Indefinite DPs are restricted by Heim's (1982) novelty condition to denote discourse-novel entities. Indefinite possessives-possessive partitive DPs whose embedded $\mathrm{DP}_{2}$ is indefinite-will thus necessarily denote part of a discourse-novel entity.

Storto ([to appear]) argues that this semantic restriction is incompatible with the derivation of a contextual reading for indefinite possessives under either of the accounts of the contextual recovery of the nature of the relation involved in possessive DPs sketched in the previous section. Linking the interpretation of the underspecified relation involved in the embedded indefinite $\mathrm{DP}_{2}$ to some contextuallysalient relation is not possible because this would lead to a violation of the novelty condition imposed on the denotation of this DP. Under a contextual interpretation of the relation holding between possessor and possessum, the embedded DP would end up denoting a discourse-familiar entity. ${ }^{5}$

Summarizing, in the analysis proposed by Storto ([to appear]) the unavailability of contextual interpretations for indefinite possessives follows from the interaction between the discourse-novelty condition imposed on the referent associated 
to their embedded $\mathrm{DP}_{2}$ and from their partitive semantics. This analysis shares with the analyses proposed by Barker (1998) and Zamparelli (1998) the assumption that indefinite possessives have an essentially partitive structure like that depicted in (5) above (the partitive hypothesis). However, differently from Barker and Zamparelli, it is proposed that indefinite possessives and possessive partitives differ in the discourse-semantic properties of their embedded $\mathrm{DP}_{2}$ : in indefinite possessives this DP cannot be definite, and thus it cannot anchor the meaning of the whole $\mathrm{DP}_{1}$ to the previous context, as instead is the case for possessive partitives.

The hypothesis that the embedded nominal in indefinite possessives is indefinite itself faces an apparent problem which I will dismiss immediately. Under the partitive hypothesis the embedded $\mathrm{DP}_{2}$ in indefinite possessives is essentially a Saxon genitive DP, a type of DP which is usually assumed to be definite. It is however known that Saxon genitives do not always trigger maximality entailments, a property typical of definite DPs. In particular, Saxon genitives can be used as predicates in copular constructions without triggering the entailment that the subject of predication is the maximal individual satisfying the predicate.

a. These [pointing left] are my dogs, and those [pointing right] are my dogs too.

b. \#These [pointing left] are all the dogs I own, and those [pointing right] are all the dogs I own, too.

The predicate which translates the VP are my dogs in (10a) cannot be interpreted as the property holding of the maximal set of dogs owned by the speaker; otherwise the sentence should be semantically deviant like the sentence in (10b) in which this maximality requirement is overtly spelled out.

In Storto ([to appear]) it is assumed that Saxon genitives in English are ambiguous between a definite and an indefinite interpretation, and that only their indefinite interpretation is licensed in the embedded position of indefinite possessives. This general constraint on the definiteness of the embedded $\mathrm{DP}_{2}$ in indefinite possessives is related to the syntactic derivation of these DPs. Following in part a proposal in Zamparelli (1998), it is assumed that the surface structure of indefinite possessives is derived from a structure similar to the surface form of possessive partitives (11a) by movement of the NP embedded in $\mathrm{DP}_{2}$ into the specifier of a projection headed by partitive of $(11 \mathrm{~b}):^{6}$

$$
\begin{aligned}
& \text { a. } \left.\left[{ }_{\mathrm{DP}_{1}} \text { some }\left[\mathrm{XP}_{\mathrm{XP}} \emptyset\left[\mathrm{x}^{\prime} \text { of } \text { part }_{\mathrm{DP}_{2}} \text { John's }\left[{ }_{\mathrm{NP}} \text { dogs }\right]\right]\right]\right]\right] \\
& \text { b. } \left.\left[_{\mathrm{DP}_{1}} \text { some }\left[{ }_{\mathrm{XP}}\left[{ }_{\mathrm{NP}} \text { dogs }\right]_{i}\left[{ }_{\mathrm{X}^{\prime}} \text { of } \text { part }_{\mathrm{DP}_{2}} \text { John's } t_{i}\right]\right]\right]\right]
\end{aligned}
$$

The restriction on the definiteness value of $\mathrm{DP}_{2}$ in (11b) can be related to some constraint on movement of the embedded NP out of a definite $\mathrm{DP}_{2}$. This constraint is reminiscent of the facts discussed at length in Fiengo and Higginbotham (1981): definite DPs are opaque for binding of variables and anaphors, which explains the pattern of (un)grammaticality displayed in (12) for Wh-movement out of various types of DPs. 
Fiengo and Higginbotham (1981) deal with instances of extraction of a complement DP from the DP in which it is embedded. The syntactic movement involved in the derivation of (11b), instead, is movement of NP out of the DP projected by the determiner which selects the NP as a complement, thus it is not immediately obvious that the movement restrictions discussed by Fiengo and Higginbotham are effective in the derivation of indefinite possessives as well. However, as pointed out to me by Kyle Johnson, restrictions parallel to those exemplified in (12) hold of syntactic configurations in which a NP seems to have undergone syntactic movement stranding its determiner, too. In split topicalization constructions in German a NP appears in sentence-initial position with its determiner stranded in a lower position in the clause. Interestingly, definite DPs cannot be used in this construction, as the contrast in (13) shows:

$$
\begin{aligned}
& \text { a. Hausaufgaben haben die Studenten nicht mal zwei gelesen. } \\
& \text { home.tasks have the students not even two read } \\
& \text { 'The students haven't read even two homework sets.' } \\
& \text { b. * Hausaufgaben haben die Studenten nicht die zwei gelesen. } \\
& \text { home.tasks have the students not the two read }
\end{aligned}
$$

If definiteness of DP blocks extraction of NP as well, the indefiniteness restriction on $\mathrm{DP}_{2}$ in double genitives follows from their syntactic derivation in (11b). $\mathrm{DP}_{2}$ in possessive partitives can be definite, instead, because these DPs do not involve movement of NP. Following Barker (1998), in Storto ([to appear]) it is assumed that possessive partitives are interpreted as if they contained a "semantically transparent" NP in the specifier of the projection of partitive of (11a).

\subsection{Converging Evidence}

The hypothesis that indefinite possessives are essentially partitive DPs in which the embedded $\mathrm{DP}_{2}$ is necessarily indefinite correctly predicts some distributional asymmetries holding between indefinite possessives and possessive partitives. For example, the contrast in (14)—unexpected under analyses like Barker's (1998)—is accounted for within the proposal outlined above. ${ }^{7}$

a. two of John's four dogs

b. *two dogs of John's four

Zamparelli (1995) notes that Saxon genitives which contain an overt numeral always trigger maximality entailments. The sentence in (15) differs from (10a) above only in that an overt numeral is inserted in the Saxon genitives in postcopular position, but whereas the latter is well-formed this sentence is semantically deviant. Both uses of the DP my four dogs in (15) introduce maximality entailments, which are incompatible with the meaning of the whole conjunctive statement. 
(15) \#These [pointing left] are my four dogs, and those [pointing right] are my four dogs too.

The facts observed by Zamparelli can be taken to indicate that Saxon genitives containing overt numerals are necessarily definite, a conclusion which directly entailsunder the current analysis - that these DPs will not be licensed in the embedded position of indefinite possessives, thus accounting for the pattern in (14). ${ }^{8}$

A second, more general prediction of the analysis proposed for indefinite possessives is that these DPs should behave like non-specific indefinites. According to Enç (1991) specific indefinites denote novel discourse entities, but impose the additional restriction that the discourse referent that they introduce is related to an already existing discourse referent (in the default case the referent of a specific indefinite DP is restricted to be part of a discourse-familiar entity). Given the indefiniteness restriction on the embedded $\mathrm{DP}_{2}$ proposed above, indefinite possessives necessarily denote part of a discourse-novel entity. The semantics of indefinite possessives is thus incompatible with the specific interpretation, which could be derived only by disregarding the discourse-semantic properties of their embedded $\mathrm{DP}_{2}$.

If indefinite possessives are necessarily non-specific it is expected that a distributional asymmetry will arise between these DPs and possessive partitives in contexts which license only specific DPs. A case in point is given by copular constructions in English, which license inversion of the pre- and post-copular nominals only when the latter is definite or specific (compare (16) to (17)).

a. John is the culprit.

b. John is a man.

c. John is one of the men I told you about.
a. The culprit is John.
b. *A man is John.
c. ?One of the men I told you about is John.

It is thus predicted that copular constructions will license inversion when the post-copular position is occupied by a possessive partitive DP, but not when the same position is occupied by an indefinite possessive. This prediction seems supported by contrasts like (18):

a. She/Mary is one of John's friends, right? ?No, one of John's friends is HIM/PETER

b. She/Mary is a friend of John's, right?

* No, a friend of John's is HIM/PETER

Inverted copular constructions involving possessive partitives are somewhat dispreferred by English speakers, but most speakers I consulted accepted the answer in (18a) as grammatical. ${ }^{9}$ On the other hand, the same speakers rejected the answer 
in (18b) as ungrammatical. Even speakers who did not find (18a) completely wellformed perceived a clear contrast when presented with $(18 \mathrm{~b})$, which was judged completely out.

The analysis proposed in Storto ([to appear]) seems to make correct predictions about the different distributional properties of indefinite possessives and possessive partitives. These predictions provide empirical support for the analysis proposed to the extent that they cannot be derived under theories like Barker's (1998) or Zamparelli's (1998), and do not immediately follow from the theory proposed in Kayne (1994) either. ${ }^{10}$ In the next section I will however address some problems raised by the analysis outlined in this section, which seem to call for a revision of the proposal.

\section{Problems}

A first problematic aspect actually follows directly from the apparently correct prediction concerning (18) discussed above. The interaction between the analysis of indefinite possessives proposed and Enç's (1991) theory of specificity does not only predict that indefinite possessives have the syntactic distribution of non-specific indefinites, but leads to the conclusion that they will never license a specific interpretation, too. To test this prediction I asked various English speakers to evaluate whether the double genitive DP in the second sentence of the discourse in (19) could be interpreted as denoting a subset of the group of John's dogs introduced in the first sentence.

(19) \% Some of John's dogs and some of Paul's dogs got loose in the street yesterday. Unfortunately two dogs of John's were hit by a passing car.

As shown by the diacritic in (19), the response was mixed: some speakers allowed for the possibility of interpreting two dogs of John's in (19) as denoting a subset of the dogs introduced in the first sentence, but other speakers judged this reading to be unavailable.

The positive response given by the first group of speakers is unexpected under the analysis of indefinite possessive proposed in Storto ([to appear]). A possible way out of this problem would be to assume that these speakers' judgments are the result of some additional pragmatic work on their part to make sense of the whole discourse, which-in some sense-overrides the semantic restrictions imposed by the grammar of double genitives. ${ }^{11}$ Assigning a specific interpretation to the double genitive in (19), if possible at all, seems to require some additional work when compared to a parallel sentence containing a possessive partitive DP in place of the double genitive. This difference, however, could be simply due to Gricean pragmatics: the availability in the grammar of unambiguously specific DPs having the same descriptive content-i.e. possessive partitives-favors a non-specific reading for double genitives.

Deciding on the availability of the discourse-specific interpretation for indefinite possessives is crucial to the evaluation of the analysis proposed in Storto 
([to appear]), but I will have to leave this issue open, decisive evidence being unavailable at the moment.

A related problem was originally pointed out to me by Gregory Ward. The prediction that double genitives are necessarily non-specific and cannot refer to entities previously introduced in the context seems to be at odds with the grammaticality of double genitives introduced by a demonstrative determiner. For example, the double genitive this dog of John's can be used to refer back to an entity which is already discourse-familiar in (20).

(20) A stray dog was captured in Griffith Park which turned out to belong to John. This dog of John's had been missing for almost six months.

I actually do not find examples like (20) to constitute a real problem for the analysis proposed. The absence of the contextual reading and the obligatory non-specificity of indefinite possessives derive from the indefiniteness restriction imposed on the embedded nominal in their partitive-like structure. Indefiniteness of $\mathrm{DP}_{2}$, however, imposes a constraint only on the entity of which the whole indefinite possessive DP denotes a part, and not on the denotation of the indefinite possessive as a whole. The constraint that the entity denoted by $\mathrm{DP}_{2}$ is discourse-novel is compatible with the discourse-familiarity of the entity denoted by the whole DP.

Under this analysis, DPs like this dog of John's in (20) indirectly introduce a new discourse referent and link it to an existing discourse referent, which denotes a part of the entity denoted by the new discourse referent. That is, indefinite possessives of this sort indirectly introduce in the discourse context the information that the entity denoted (the dog referred to in (20)) is part of a bigger set of entities which satisfy the "descriptive content" of the DP itself (John's $\operatorname{dog}(s)$ in (20)). ${ }^{12}$

A more serious problem I see with the analysis of indefinite possessives proposed in Storto ([to appear]) is that it is not immediately compatible with a version of the Partitive Constraint which is quite often adopted (under various formulations) in the literature. This constraint states that the DP embedded under partitive of is necessarily an entity-denoting expression (this is the formulation in Ladusaw (1982)), and is intended to account, among others, for the intuition that (21) is grammatical in English only under a specific interpretation of three people. Indefinite DPs denote entities when they receive a specific interpretation, thus only under this interpretation can they appear in the embedded position in partitive DPs. ${ }^{13}$

\section{(21) That book could belong to one of three people.}

If indefinite possessives are partitive constructions, as argued above, they should be subject to the Partitive Constraint as well. In particular, given the assumption that $\mathrm{DP}_{2}$ in indefinite possessives is indefinite, it is expected that this DP is restricted to a specific interpretation as well. But this conclusion is not compatible with the derivational account for the existence of an indefiniteness constraint on $\mathrm{DP}_{2}$ in indefinite possessives proposed in Storto ([to appear]). Indeed, as argued in Fiengo (1987), specific indefinites seem to be as opaque as definite DPs, blocking extraction of embedded DPs. And the same conclusion holds for split topicalization 
constructions in German, which are not licensed for scrambled indefinites (which are normally argued to receive a specific interpretation):

$$
\begin{array}{ll}
\text { *Hausaufgaben haben die Studenten zwei nicht mal gelesen. } \\
\text { home.tasks have the students two not even read }
\end{array}
$$

The derivational account of the indefiniteness restriction on the embedded $\mathrm{DP}_{2}$ in indefinite possessives cannot be maintained under Ladusaw's formulation of the Partitive Constraint. In the next section I will outline some possible ways of tackling this problem.

\section{Some Revisions}

In principle, two alternative lines can be pursued in revising the analysis proposed. The hypotheses that indefinite possessives are partitive constructions with an indefinite $\mathrm{DP}_{2}$ and that the necessary indefiniteness of $\mathrm{DP}_{2}$ is due to the extraction of NP can be maintained if $\mathrm{DP}_{2}$ in partitives is not restricted to denoting an entity. That is, Ladusaw's formulation of the Partitive Constraint could be abandoned.

In effect, the exact nature of the Partitive Constraint is still quite a thorny issue in the literature. Various formulations of this constraint have been defended and some authors (e.g. Abbott (1996)) have even proposed to abandon the idea that partitives are subject to grammatical constraints, and suggest that pragmatic principles determine the well-formedness of partitives.

For the analysis of indefinite possessives outlined in Section 4 to be maintained in its entirety, the possibility has to be left open that the embedded nominal in partitives can be a set-denoting indefinite DP. De Hoop (1997) proposes a formulation of the Partitive Constraint which allows for this configuration to obtain. De Hoop argues that two types of partitives should be distinguished-entity partitives and set partitives - the first being partitive constructions in which the upstairs determiner quantifies over entities and the second being constructions in which this determiner quantifies over restricted sets of entities. The Partitive Constraint is reformulated as the requirement that entity-denoting DPs appear in entity partitives, and that set-denoting DPs appear in set partitives. ${ }^{14}$

Within De Hoop's analysis even the embedded DP in partitives like two of the dogs is a set-denoting DP. The numeral two is a quantificational determiner that takes sets of entities as first argument, thus-by the Partitive Constraint-the dogs must denote a set of entities. This follows if the definite article is not a real determiner, but a context-set indicator which signals that the denotation of a NP is restricted to a contextually-salient set of entities which satisfy the descriptive content of the NP itself. Definite DPs in the embedded position of set partitives thus denote contextually-restricted sets of entities.

De Hoop proposes that the embedded DP in set partitives is subject to the additional restriction that it denotes a unique restricted set. This further requirement accounts for the asymmetries attested in the distribution of definite vs. indefinite 
DPs in the embedded position in set partitives. Whereas the unique denotation of definite DPs can always be determined by the context, indefinite DPs do not always uniquely refer but they can do so when they receive a specific interpretation or when they are syntactically modified. Only under these two conditions, then, are indefinite DPs licensed in set partitives.

The discourse-semantic distinction I postulated between the embedded DPs in possessive partitives like (23a) and indefinite possessives like (23b) still plays a role within the analysis of partitives proposed in de Hoop (1997). The embedded DP John's dogs in (23a) can be definite, and thus it can contextually identify the reference set on which the determiner two quantifies. The embedded DP John's dogs in (23b), instead, is necessarily indefinite and cannot retrieve the reference set from the context. The upstairs determiner in indefinite possessives will necessarily quantify over a discourse-novel set of entities. ${ }^{15}$

$$
\text { a. two of John's dogs }
$$

b. two dogs of John's

Reformulating the Partitive Constraint along the lines proposed by De Hoop solves the problem for the derivational account of the indefiniteness restriction on the embedded DP in indefinite possessives. This indefinite set-denoting DP is syntactically restricted by the possessor nominal. The embedded DP in indefinite possessives denotes the maximal set of entities which satisfy the descriptive content of the possessum nominal and which are related to the possessor; thus it does not need to receive a specific interpretation to have unique reference.

An alternative possibility is that of revising the analysis proposed in the previous sections by giving up some of the assumptions on which it is based. The easiest option is to give up the idea that the indefiniteness restriction on $\mathrm{DP}_{2}$ follows from constraints on extraction of NP. Once this assumption is abandoned, the restriction that $\mathrm{DP}_{2}$ in partitives is entity-denoting does not constitute a problem for the analysis. Even under the specific interpretation imposed by the Partitive Constraint in Ladusaw (1982), $\mathrm{DP}_{2}$ in indefinite possessives would still be restricted to denoting a discourse-novel entity, deriving the unavailability of the contextual interpretation for the whole DP in which it is embedded. In the reformulated analysis, though, the indefiniteness restriction on $\mathrm{DP}_{2}$ in indefinite possessives would be simply stipulated, rather than accounted for.

A more radical move is that of abandoning the partitive hypothesis as a whole. However, if the hypothesis that indefinite possessives are partitive constructions is discarded, most of the data accounted for under the assumption of the partitive hypothesis become problematic again. The account proposed for the unavailability of contextual interpretations (and more generally discourse-specific interpretations) crucially relies on the partitive semantics of indefinite possessives: the discourse-semantic properties of the embedded DP in their partitive structure determine their peculiar semantic properties. Again, the unavailability of the contextual interpretation for indefinite possessives cannot be simply explained in terms of their indefiniteness: indefinite DPs in general can be interpreted as denoting (part of) discourse-familiar entities. 
That the definite vs. indefinite specification of a possessive DP as a whole cannot be the determinant for the availability of the contextual interpretation is further argued by data like (24):

(24) \# Yesterday John and Paul were attacked by (different) groups of dogs. Unfortunately the dogs of John's that were captured turned out to be rabid.

The possessive DP the dogs of John's that were captured is arguably definite, but it has the morphology of a double genitive DP. Interestingly, this possessive DP does not license a contextual interpretation in (24). Definite double genitives behave in this respect exactly like indefinite double genitives, and the same holds for demonstrative double genitives of the kind discussed in (20). The conclusion is that the unavailability of contextual interpretations for indefinite possessives must be tied to their syntactic/semantic structure, which distinguishes them from both definite possessives and possessive partitives.

If the partitive hypothesis is abandoned, some other structural property of indefinite possessives must be resorted to in order to account for their semantic peculiarity. A direction which seems worth exploring is that of considering whether the peculiarity of indefinite possessives could be derived in terms of the predicative nature of the phrase which follows of in these DPs. Such an analysis would build on the parallelism between the sentences in (25) and the possessive DPs in (23).

a. these are John's dogs

b. these dogs are John's

(25a) can be interpreted both as a predicative construction and as an identificational statement, but (25b) can only be interpreted as a predicative construction because the post-copular material cannot be interpreted as a referential XP.

Interestingly, my informants tell me that only (25a) licenses a contextual reading, whereas (25b) does not. That is, only the first sentence could be used in a context similar to that in (7) to state that the objects pointed at are the dogs which attacked John. The unavailability of the contextual reading for indefinite possessives like (23b), then, could be possibly derived in terms of the non-referential status of John's. ${ }^{16}$ At this point I do not have a clear idea of how (and whether) an analysis along these lines could be implemented to derive the properties of indefinite possessives pointed out in this paper. ${ }^{17}$

\section{Conclusions: The Crosslinguistic Perspective}

I argued that the semantic asymmetry existing between indefinite possessives vs. definite possessives and possessive partitives examined in this paper is indicative of a syntactic/semantic structural distinction between indefinite possessives and either of the other two types of possessives licensed in English. The structure of indefinite possessives seems to be more complex than the structure of definite possessives. 
Following Storto ([to appear]) I proposed that indefinite possessives have a partitive structure, but differ from the corresponding possessive partitives in the discoursesemantic properties of the DP embedded under partitive of. I furthermore pointed out some problematic aspects of this analysis, and I have shown that a derivational analysis of the indefiniteness restriction on the embedded DP in indefinite possessives can be maintained under a reformulation of the Partitive Constraint along the lines proposed by de Hoop (1997).

In the analysis proposed the unavailability of contextual interpretations for indefinite possessives in English is a reflex of their inherently non-(discourse-)specific semantics. A precise assessment of the status of discourses like (19) is therefore crucial in evaluating the correctness of this proposal. Even in the event that indefinite possessives are actually able to license discourse-specific interpretationswhich would entail a rejection of the analysis presented above-I hope to have at least shown that indefinite possessives in English are structurally more complex than definite possessives, and that their semantics differs from the latter's beyond what their indefinite vs. definite specification would lead one to expect.

The conclusions reached for English directly extend to languages like Italian. Their seemingly equal morphological complexity notwithstanding, indefinite possessives in Italian differ from definite possessives (and from possessive partitives) exactly as in English. Indefinite possessives do not license contextual interpretations and do not seem to receive discourse-specific interpretations either. Within the analysis proposed in this paper, this is a reflex of their syntactic/semantic structure, which is more complex than what their surface morphological structure seems to indicate. ${ }^{18}$

This analysis raises the question-addressed in Dobrovie-Sorin (199x) but, in my opinion, not completely resolved there-why indefinite possessives, across languages, do not have a simpler structure, similar to that of definite possessives. Their semantics seems to indicate that indefinite possessives always have a partitivelike structure, in which the determiner is interpreted as a quantificational expression, and do not license an "adjectival" interpretation of their determiners (like other indefinite DPs do). This issue is hereby left open for future investigation.

\section{Endnotes}

* The talk I delivered at the conference was titled "Indefinite possessives are indefinite, after all." I would like to thank the audiences of SALT 10, CLS 36, and the UCLA Linguistics syntax/semantics seminar for their input on the topics dealt with in this paper. Chris Barker, Edward Garrett, Kyle Johnson, Ed Keenan, Chris Kennedy, Hilda Koopman, Jason Merchant, Ivan Sag, Barry Schein, Carson Schütze, Dominique Sportiche, Gregory Ward, and Karina Wilkinson kindly provided me with comments and thorough criticism. Misha Becker, Ivano Caponigro, Leston Buell, and Harold Torrence helped me with the data and/or proofreading. I would like to dedicate this work to the memory of Martin Honcoop. 
1 XP denotes the set of entities which are proper parts of the entity denoted by the embedded $\mathrm{DP}_{2}$. The denotation of XP will thus always be a lattice without its top and bottom elements, a structure on which the maximality operator which translates the definite determiner does not apply because of its lacking a unique maximal element. Additional modification of XP can successfully filter out some elements in its denotation, obtaining a structure with a unique maximal element.

2 Ivan Sag pointed out to me that for him indefinite possessives like some dogs of John's are pretty marginal even under the "ownership" interpretation. Like a few other speakers I consulted, he seems to accept double genitives only when the possessum nominal is a relational noun. This behavior is indeed expected if this interpretation - as argued in Barker (1995) - is contextually determined as well. See the following two notes and the corresponding paragraphs in the main text.

3 In this paper I will not be concerned with lexical possessives, which can be argued to be structurally distinct from extrinsic possessives (see, among others, the discussion in Dobrovie-Sorin (199x)).

4 Barker accounts for the felicitousness of discourse-initial possessives under the "ownership" interpretation by assuming that the relation of possession proper is contextually salient "by default," being accommodated in the empty context at the lowest cost possible. Another option would be that of assuming that this interpretation of possessive DPs is syntactically specified. Possibly, the dialectal variation between speakers who accept double genitives in which the possessum is a nonrelational noun and those who license double genitives only with relational possessums could be explained in terms of lexicalization of the "ownership" interpretation.

5 Here the assumption is implicit that the indefinite interpretation of John's dogs in the embedded position in indefinite possessives still denotes a unique set (i.e. the maximal set of dogs which stand in the underspecified relation to John).

6 That NP movement, rather than NP ellipsis, is involved in double genitives can be argued on the basis of the data in (i)-(ii):

i. *I like two dogs of your dogs.

ii. John $\mathrm{J}_{i}$ told that [story about his $i$ mother] of Bill's.

Double genitives do not license overt spell out of the "missing" NP (i), nor do they license sloppy readings for pronouns ((ii); from Johnson (1997)), properties which characterize NP ellipsis.

7 A handful of speaker that I consulted seemed to accept (14b) as grammatical. Most likely they reinterpreted this DP as (i), which is grammatical.

i. two dogs out of John's four

ii. two dogs out of John's four dogs

(i) and (14b) are different constructions, however: double genitives do not license overt spell out of the missing NP but DPs like (i) allow for this possibility (ii).

8 The deviance of (14b) cannot be due to an alleged ungrammaticality of the NPless DP John's four, which is indeed licensed in NP-ellipsis contexts like (i):

i. These [pointing left] are Mary's three dogs, and those [pointing right] are John's four. 
9 Small caps mark contrastive focus intonation. The speakers that I consulted seemed to accept inverted copular constructions more easily in the contrastive-reply context exemplified in (18).

10 As a matter of fact, the contrast in (14) does follow from Kayne's analysis: if indefinite determiners in double genitives are generated in NP/QP, the ungrammaticality of (14b) can be reduced to the ungrammaticality of *John's two four dogs. The contrast in (18), however, is not expected: nothing in Kayne's analysis leads to the expectation that double genitives behave like non-specific indefinites.

11 The fact that the contextual interpretation cannot be rescued in the same way is problematic, under this assumption.

12 The conclusion that DPs like this dog of John's in (20) actually introduce the entailment that John owns (or owned) more than one dog is supported by the fact that nouns whose denotation is unique cannot appear in this construction; witness the ungrammaticality of *this mother of John's.

13 Van Geenhoven (1998) argues that the specific interpretation at stake in (21) which involves a wide-scope interpretation of the indefinite DP-should not be confused with discourse-specificity (which she calls partitivity). I agree with van Geenhoven that this is the case, but I decided to follow the terminology which is widely used in the literature.

14 De Hoop (1997) adopts a different perspective on the syntax/semantics of partitives from the one adopted in Barker (1998). In her analysis the role of partitive of is that of making the denotation of the embedded DP available as quantification domain for the upstairs determiner.

15 Indefinite DPs, which can receive a discourse-specific interpretation, are not subject to this restriction. When the numeral two in two dogs is interpreted as a quantificational determiner (rather than as an adjective), its domain of quantification can be determined by restricting the denotation of the NP dogs to the unique set of dogs salient in the context.

16 An analysis along these lines would be able to account for the ungrammaticality of (14b), given that John's four cannot be used predicatively. This analysis is further supported by the intuition that John's dogs under a contextual interpretation carries maximality entailments even in post-copular position.

17 In particular, it is not clear to me how this proposal could, if needed, derive the absence of a discourse-specific interpretation in indefinite possessives. Deriving the semantic distinction between indefinite and definite possessives might even require distinguishing between the syntactic/semantic role of John's in (23b) and the role of John's in definite DPs like John's two dogs.

18 Italian is, in a way, more "ambiguous" than English: the different structures of definite and indefinite possessives have the same phonological output. For example, where the English double genitive in (24) clearly does not license a contextual interpretation, the Italian $i$ cani di Gianni che sono stati catturati is harder to evaluate in the same context. This might be due to the fact that this Italian DP can correspond to both the structure of (24) and that of John's dogs that were captured, which-my informants tell me-licenses a contextual interpretation. 


\section{References}

Abbott, Barbara 1996. Doing without a partitive constraint. In Jacob Hoeksema (ed.), Partitives, pp. 25-56. Berlin: Mouton de Gruyter.

Barker, Chris 1995. Possessive Descriptions. Stanford, Ca.: CSLI Publications.

Barker, Chris 1998. Partitives, double genitives, and anti-uniqueness. Natural Language and Linguistic Theory, 16(4):679-717.

de Hoop, Helen 1997. A semantic reanalysis of the partitive constraint. Lingua, 103:151-174.

den Dikken, Marcel 1998. Predicate inversion in DP. In Artemis Alexiadou and Chris Wilder (eds.), Possessors, Predicates and Movement in the Determiner Phrase. Amsterdam: John Benjamins.

Dobrovie-Sorin, Carmen 199x. De la syntaxe à l'inteprétation, de Milner (1982) à Milner (1995): Le génitif. Manuscript. Université Paris 7, Paris.

Enç, Mürvet 1991. The semantics of specificity. Linguistic Inquiry, 22(1):1-25.

Fiengo, Robert 1987. Definiteness, specificity, and familiarity. Linguistic Inquiry, 18(1):163-166.

Fiengo, Robert and James Higginbotham 1981. Opacity in NP. Linguistic Analysis, 7(4):395-421.

Heim, Irene 1982. The Semantics of Definite and Indefinite Noun Phrases. Ph.D. thesis, University of Massachusetts, Amherst.

Johnson, Kyle 1997. A review of The Antisymmetry of Syntax. Lingua, 102:21-53.

Kayne, Richard 1994. The Antisymmetry of Syntax. Cambridge, Mass.: MIT Press.

Ladusaw, William 1982. Semantic constraints on the English partitive construction. In Proceedings of the First West Coast Conference on Formal Linguistics. Stanford, Ca.: CSLI Publications.

Storto, Gianluca [to appear]. Double genitives aren't (quite) partitives. In Papers from the Thirty-Sixth Regional Meeting of the Chicago Linguistic Society. Chicago, Ill.: CLS, University of Chicago.

van Geenhoven, Veerle 1998. Semantic Incorporation and Indefinite Descriptions. Stanford, Ca.: CSLI Publications.

Zamparelli, Roberto 1995. Layers in the Determiner Phrase. Ph.D. thesis, University of Rochester.

Zamparelli, Roberto 1998. A theory of kinds, partitives and $\mathrm{OF} / \mathrm{Z}$ possessives. In Artemis Alexiadou and Chris Wilder (eds.), Possessors, Predicates and Movement in the Determiner Phrase. Amsterdam: John Benjamins.

3125 Campbell Hall, UCLA

Box 951543

Los Angeles, CA 90095-1543

storto@ucla.edu 